\title{
Magneto-mechanical Design and Development of a Coaxial Magnetic Coupling with Optimization of Torque to Mass Ratio
}

\author{
Oliver Tweedy \\ PEMC Research Group \\ University of Nottingham \\ Nottingham, UK \\ oliver.tweedy1@nottingham.ac.uk
}

\author{
Yusuf Akcay \\ PEMC Research Group \\ University of Nottingham \\ Nottingham, UK \\ yusuf.akcay1@nottingham.ac.uk \\ Michael Galea \\ Key Laboratory of More Electric Aircraft \\ Technology of Zhejiang Province \\ University of Nottingham \\ Ningbo, China \\ michael.galea@nottingham.ac.uk
}

\author{
Paolo Giangrande \\ PEMC Research Group \\ University of Nottingham \\ Nottingham, UK \\ p.giangrande@nottingham.ac.uk
}

\begin{abstract}
This work covers the design and analysis of a coaxial magnetic coupling with the aim to optimize the torque to mass ratio. Magnetic couplings provide several unique benefits over standard mechanical couplings that are made possible via magnetic torque transmission including reduced maintenance, greater tolerance for misalignment and intrinsic overload protection. The main disadvantage of magnetic couplings is that their torque to mass ratio is significantly lower than equivalent mechanical couplings. 2D magnetostatic and 3D finite element mechanical models are used to analyze the proposed coupling geometry and ensure it can transfer a maximum torque of $224 \mathrm{Nm}$ and operate at a steady rotational speed of 1000 RPM. The relationship between the magnetic design parameters (pole pairs number, air gap, etc.) and the target performance parameters (torque and relative rotor angle) are established and used to develop a rotor geometry that maximizes the peak static torque. $A$ parametric static stress analysis of the coupling geometry is also performed to reduce its mass and obtain an optimal torque to mass ratio. Finally, the torque to mass ratio of the optimized magnetic coupling is compared with mechanical couplings to demonstrate improved practicality of the design.
\end{abstract}

Keywords-Magnetic coupling, finite element analysis, contactless torque transmission, special machine, torque to mass ratio, stress analysis, modal analysis

\section{INTRODUCTION}

Torque/speed transmission between rotating machinery is traditionally achieved via mechanical couplings placed between shafts, which are either rigid, or flexible assemblies that physically connect the shafts together to transmit mechanical power. The ever-growing need for industries to reduce operating costs, improve reliability and reduce downtime of rotating machinery requires necessary development and adaptation of alternative technologies [1], [2] such as magnetic couplings. Contactless torque/speed transmission has an immense potential to succeed in this regard over conventional mechanical counterparts. The most common magnetic coupling configurations; i.e. axial and radial [3], have the potential to outperform conventional mechanical couplings with their highly efficient operation as well as reduced maintenance requirements, less acoustic noise and inherent overload protection [4], [5]. In particular, the coaxial magnetic coupling (CMC) design, with permanent magnets (PMs) positioned on both the load side rotor and the drive side rotor, produces a higher coupling torque when compared to other types of magnetic coupling such as eddy current couplings. Advancements in rare earth magnets have contributed to a rise in interest in magnetic couplings [6] since their original inception, making them a more practical option in modern machine applications [7]. The main disadvantage of magnetic couplings is their relatively low torque density [8] which typically results in higher initial costs (that may be offset by reduced maintenance costs), more mass/volume and a limited maximum torque capacity compared to equivalent mechanical couplings. The coaxial magnetic coupling explored in this paper is intended for use in aerospace applications. The total mass of the rotors is a significant factor in deciding the suitability of such couplings due to the need for low weight components in modern aircraft design [9]. To minimise the total mass of the magnetic coupling, the stress within the rotor cores under rated load conditions must be understood. Previous studies [10] have simulated the stress within the rotor core teeth, demonstrating that a CMC that is optimised to transfer maximum torque per unit volume will also be structurally capable of transferring a theoretically much larger torque. There is therefore significant room for mass reduction in the design of CMCs.

The existing literature on CMCs mainly gives a clear perspective on their operational limits by simply plotting the static torque by varying the relative rotor angle. Simple analytical expressions to calculate static torque are also introduced in [11] for axial configuration. When designing the magnetic coupling it is also important to take into account the structural demands placed upon it by the applied working forces.

This paper introduces the design and analysis of a CMC to determine the optimal magneto-mechanical performance of the device. The paper first explains the general overview of the $\mathrm{CMC}$, then a sensitivity analysis is performed to analyze the important magnetic design parameters such as pole pairs 
number, airgap thickness and PM span to obtain an optimized coupling configuration in terms of magnetic performance. The paper then continues with static and dynamic structural analyses to validate the performance of the coupling and ensure its capability to withstand the applied forces. A mechanical parametric analysis is undertaken to maximize the torque to mass ratio by minimizing rotor mass whilst maintaining the same peak static torque. The torque to mass ratio of the coupling is compared with existing commercially available mechanical couplings to highlight the minimum increase in weight that comes with replacing a fully mechanical coupling with a CMC. Modal analysis is performed on the final magnetomechanical optimized rotor design to determine the natural frequencies, critical speeds and mode shapes.

\section{Magnetic Coupling PARAmeters And SPECIFICATIONS}

This section gives an overview of the CMC architecture, along with the specified performance target values and the outline of the manufactured prototype based on the 2D static finite element (FE) and 3D FE mechanical analyses. An overview of the CMC dimensions is detailed in Fig. 1. In the design process, the coupling is analyzed under different essential design parameters, i.e. pole pairs number, airgap thickness and PM span. The size parameters are identified as highlighted in Fig.1 and given in Table I. The PMs are in parallel magnetization with a width of $10 \mathrm{~mm}$ and a thickness of $5 \mathrm{~mm}$. The axial length and airgap thickness are $40 \mathrm{~mm}$ and $2 \mathrm{~mm}$, respectively. The outcomes of the sensitivity analysis that characterized the $\mathrm{CMC}$ magnetic design process are discussed in Section III.

\section{A. Design Concept and Considerations}

The CMC is designed to fulfil the torque and speed values listed in Table II. The operational principal of the CMC ensures the contactless torque/speed transmission between motor and load sides. Based on the magnetic sensitivity analysis findings, the CMC prototype was built and assembled. Fig. 2 illustrates a cross sectional view through the assembled $\mathrm{CMC}$, while the assembled $\mathrm{CMC}$ along with its inner and outer rotors are shown

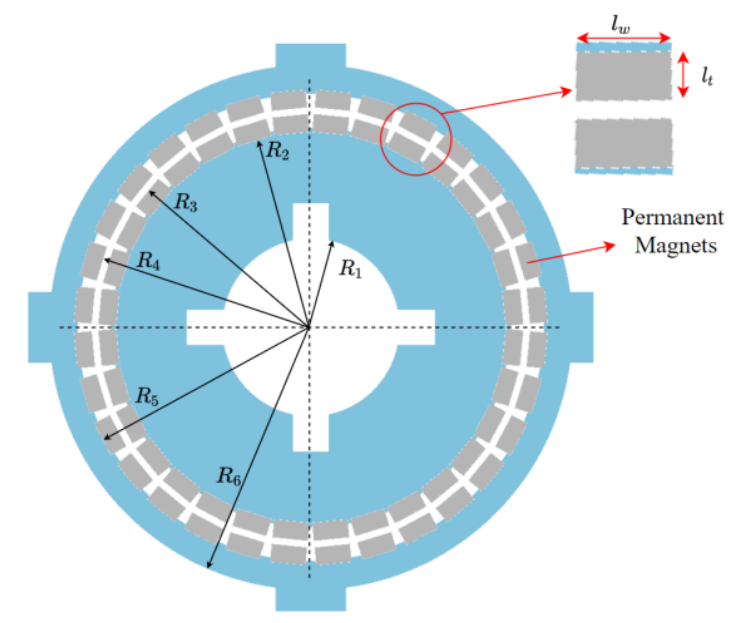

TABle i. Design Parameters of the CMC

\begin{tabular}{|c|c|}
\hline Symbol & Parameters \\
\hline$R_{I}$ & Inner Core Radius \\
\hline$R_{2}$ & Inner PM Inner Radius \\
\hline$R_{3}$ & Inner PM Outer Radius \\
\hline$R_{4}$ & Outer PM Inner Radius \\
\hline$R_{5}$ & Outer PM Outer Radius \\
\hline$R_{6}$ & Outer Core Radius \\
\hline$l_{a}$ & Airgap Thickness \\
\hline$l_{t}$ & PM Thickness \\
\hline$l_{w}$ & PM Width \\
\hline$l_{s}$ & Active Part Length \\
\hline
\end{tabular}

TABLE II. CMC SPECIFICATIONS AND DIMENSIONS

\begin{tabular}{|c|c|}
\hline Specification & Value \\
\hline Mechanical Power (kW) & 23.5 \\
\hline Mechanical Speed (RPM) & 1000 \\
\hline Torque (Nm) & 224 \\
\hline Pole-Pair Number (-) & 16 \\
\hline Permanent Magnet Thickness (mm) & 5 \\
\hline Airgap Thickness (mm) & 2 \\
\hline Axial Length (mm) & 40 \\
\hline Outer Diameter (mm) & 148 \\
\hline Active Parts Mass (kg) & 4.13 \\
\hline
\end{tabular}

in Fig $3 \mathrm{a}$ and $3 \mathrm{~b}$. The inner rotor holds a laminated rotor core composed of steel grade EN 10106, which in turn supports a radial arrangement of PMs made of Neodymium N42 with 1.29 $T$ residual magnetization, which are spaced apart and supported by a series of small teeth built into the rotor cores and used as guidance for the PMs placement.

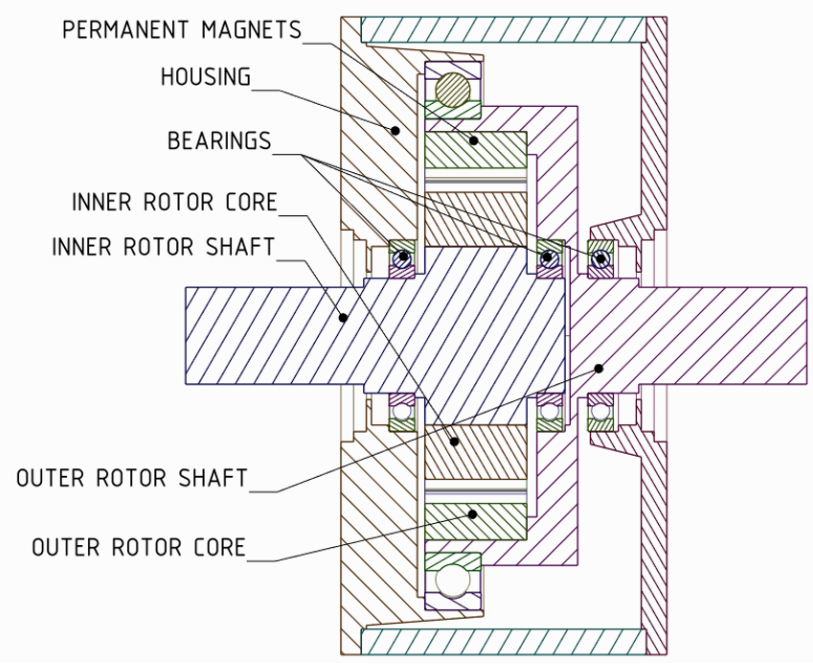

Fig. 2. Cross sectional view through the assembled CMC

Fig. 1. 2D schematic of the CMC with size parameters 


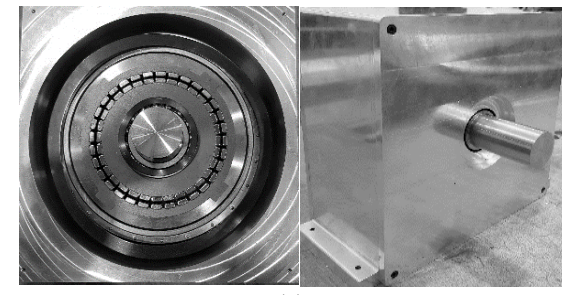

(a)

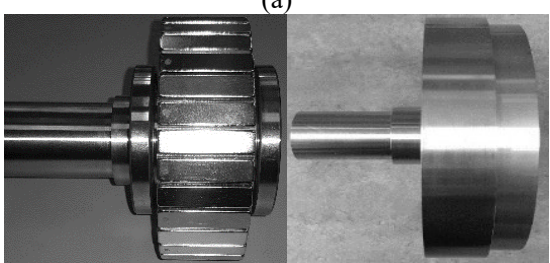

(b)

Fig. 3. (a) The CMC prototype complete overview, (b) the inner (left) and the outer (right) rotors.

TABLE III. CMC MATERIAL PROPERTIES

\begin{tabular}{|c|c|c|c|}
\hline $\begin{array}{c}\text { Rotor } \\
\text { Component }\end{array}$ & Material & $\begin{array}{c}\text { Yield Strength } \\
\text { (Min) (MPa) }\end{array}$ & Mass (kg) \\
\hline $\begin{array}{c}\text { Inner rotor } \\
\text { shaft }\end{array}$ & $\begin{array}{c}\text { Stainless steel } \\
316\end{array}$ & 205 & 1.84 \\
\hline $\begin{array}{c}\text { Outer rotor } \\
\text { shaft }\end{array}$ & $\begin{array}{c}\text { Stainless steel } \\
316\end{array}$ & 205 & 5.83 \\
\hline $\begin{array}{c}\text { Inner rotor core } \\
\text { Electrical steel } \\
\text { EN 10106 }\end{array}$ & 200 & 2.08 \\
\hline $\begin{array}{c}\text { Outer rotor } \\
\text { core }\end{array}$ & $\begin{array}{c}\text { Electrical steel } \\
\text { EN 10106 }\end{array}$ & 200 & 0.96 \\
\hline $\begin{array}{c}\text { Permanent } \\
\text { magnets }\end{array}$ & $\begin{array}{c}\text { Neodymium } \\
\text { N42 }\end{array}$ & 77 & \\
\hline
\end{tabular}

The outer rotor supports a similar, but inversed rotor core and PM assembly which permits insertion of the inner rotor, thus completing the magnetic circuit between the two CMC rotors. Table III provides the preliminary mass and material properties for each CMC component; the yield strength is used as a design limit for maximum stress in the mechanical parametric analysis carried out in Section IV.

\section{MAGNETIC ANALYSIS}

The aim of the sensitivity analysis is to explore the optimum parameters in terms of torque to mass ratio from a magnetic perspective. Fig. 4a considers the effects of the pole pairs number against different airgap thicknesses on the peak static torque. The analysis clearly shows that the optimum value of the peak static torque occurs at different pole pairs number when the airgap thickness varies. For the sake of mechanical integrity, a $2 \mathrm{~mm}$ airgap thickness is selected. A second magnetic trade-off analysis was performed with the purpose of investigating the effects of the PM span while changing pole pairs number. As it can be seen in Fig. 4b, the PM span does not change the peak static torque trend. Thus, the PM span is decided according to the PM assembly (i.e. 0.95 represents the best compromise between PM volume and leakage flux where the flux lines do not cross the airgap and go through the adjacent

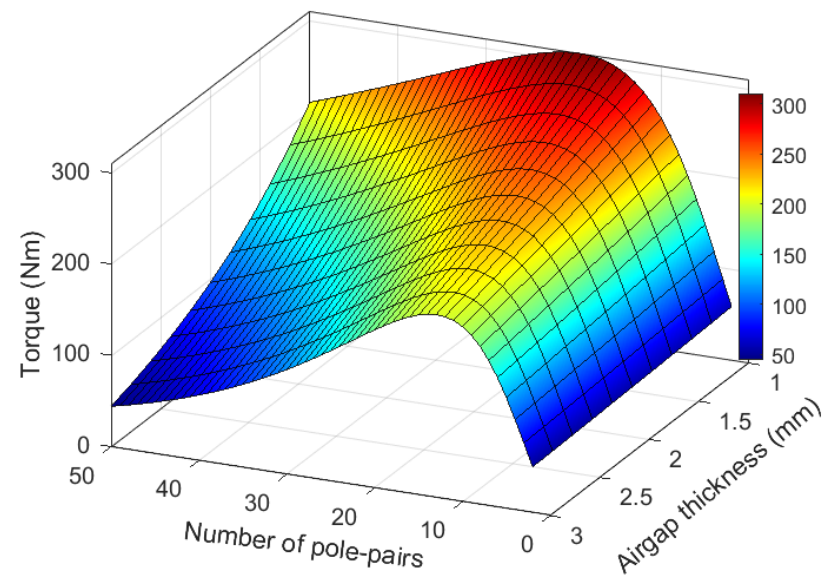

(a)

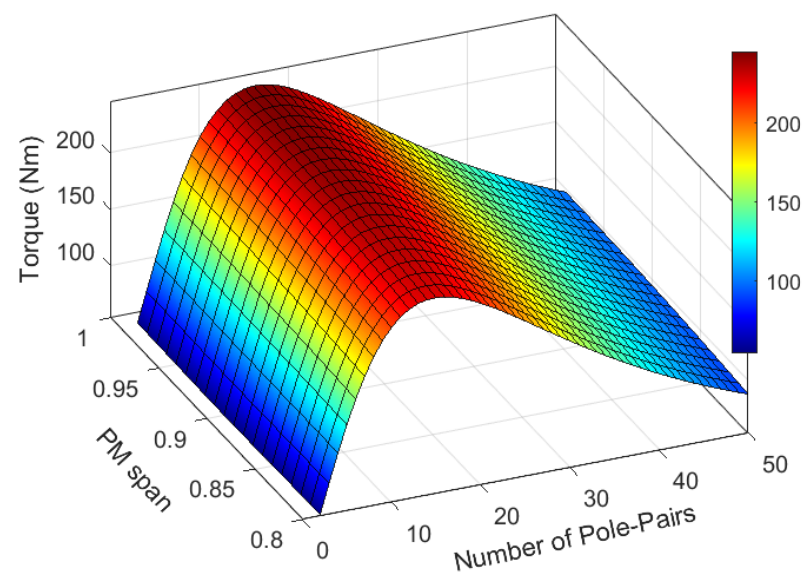

(b)

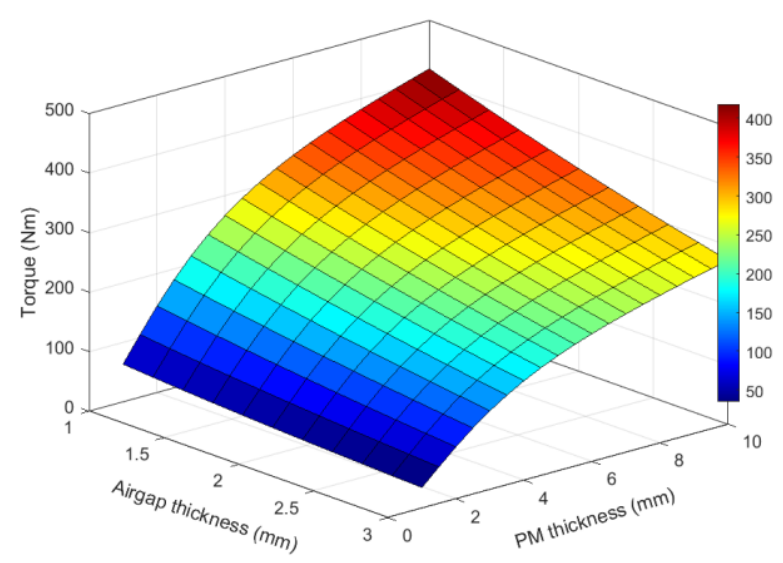

(c)

Fig. 4. (a) Peak static torque vs. pole pairs number and airgap thickness, (b) Peak static torque vs. pole pairs number and PM span, (c) Peak static torque vs. airgap and PM thicknesses.

PMs). Similarly, Fig. 4c shows the trend of the static torque when PM thickness is changed. It is evident that the PM thickness linearly changes the peak static torque. Thus, the value can be selected according to the peak static torque requirement. 


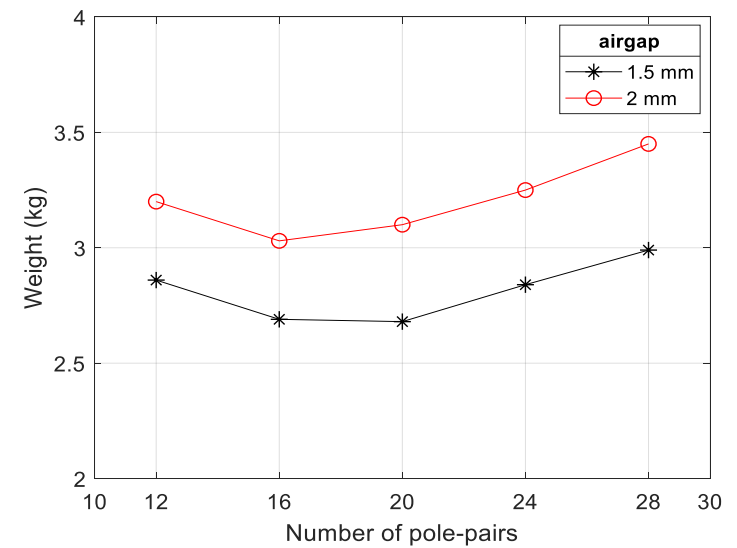

(a)

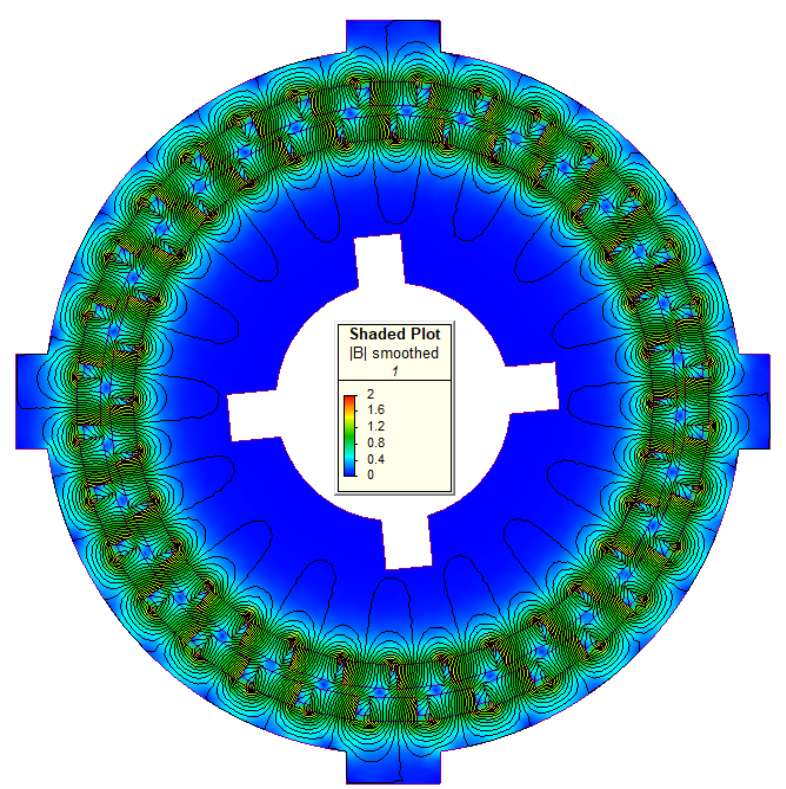

(b)

Fig. 5. (a) Active part mass vs. no. pole pairs, (b) Shaded flux plot of the $\mathrm{CMC}$ at the maximum peak torque angle.

The mass comparison is performed by taking the best pole pairs number while keeping a $2 \mathrm{~mm}$ airgap thickness. Fig. 5a reveals the active part mass against different pole pairs number. The minimum mass while keeping the same peak static torque of $224 \mathrm{Nm}$ is attained at 16 pole pairs number. Thus, the prototype is built featuring the parameters already given in Table II. Additionally, Fig $5 \mathrm{~b}$ reports the flux density map of the magnetic-optimized CMC, when the maximum peak torque angle is considered.

\section{MECHANICAL ANALYSIS}

Following the completion of the optimized magnetic design for the $\mathrm{CMC}$, the mechanical optimization is carried out to ensure the structural integrity of the design and further improve the torque to mass ratio.

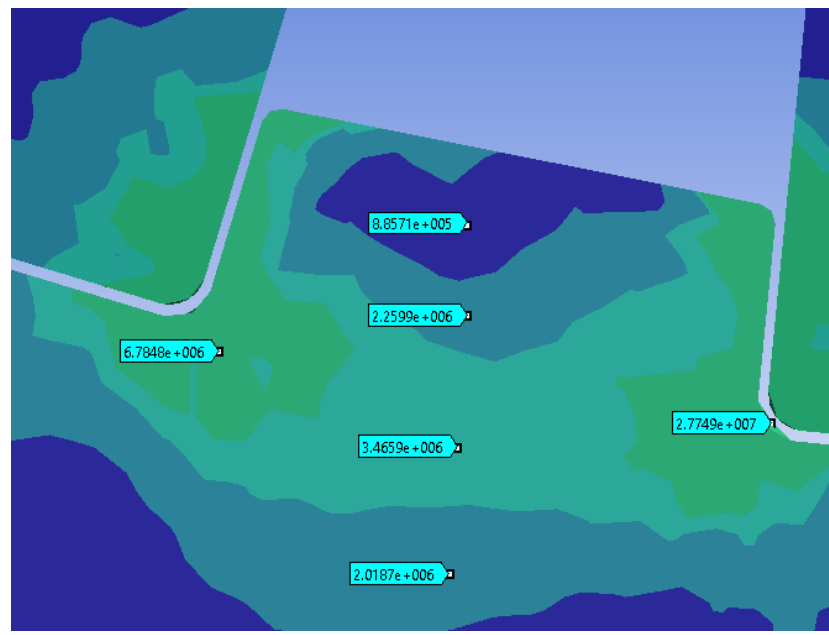

Fig. 6. Equivalent von-Mises stress in the outer core teeth.

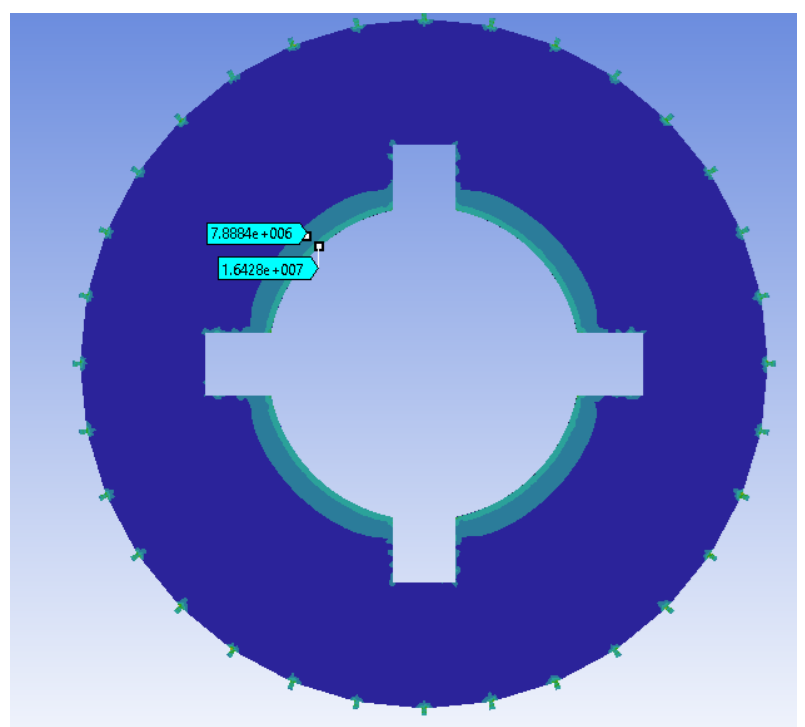

Fig. 7. Equivalent von-Mises stress in the inner core.

TABLE IV. STRESS IN COMPONENTS AT RATED LOAD

\begin{tabular}{|c|c|c|c|}
\hline Component & $\begin{array}{c}\text { Maximum } \\
\text { Equivalent } \\
\text { Stress (MPa) }\end{array}$ & $\begin{array}{c}\text { Design } \\
\text { Equivalent } \\
\text { Stress (von- } \\
\text { Mises) Limit } \\
\text { (MPa) }\end{array}$ & $\begin{array}{c}\text { Design Shear } \\
\text { Stress Limit } \\
\text { (MPa) }\end{array}$ \\
\hline Inner rotor shaft & 34 & 118.36 & 78.9 \\
\hline $\begin{array}{c}\text { Outer rotor } \\
\text { shaft }\end{array}$ & 34 & 118.36 & 78.9 \\
\hline Inner core & 16.4 & 163.33 & 94.3 \\
\hline Outer core teeth & 27.7 & 163.33 & 94.3 \\
\hline
\end{tabular}

\section{A. Structural Stress Analysis}

Static structural stress analysis is performed for the rated steady state operating condition of the coupling. The maximum equivalent (von- Mises) stress for the following components is obtained and evaluated against the maximum allowable design 
stress. A factor of safety (FoS) of 1.5 (typical for light electrical machine rotors and aircraft components [12]) is applied to the material yield stress for each component to obtain the allowable design stress. A rotational speed of 1000 RPM is applied to all rotating components and the maximum static torque of $224 \mathrm{Nm}$ is applied to the surface of the PMs on both rotors. Table IV presents the resulting maximum equivalent stress obtained from the static structural analysis performed on the CMC design under the rated operating conditions. Fig. 6 and Fig. 7 show the equivalent stress plots for the inner and outer rotor cores with the locations of highest stress noted in the outer core teeth and inner core shaft bore.

\section{B. Parametric Analysis for Mass Reduction}

To achieve the objective of increasing the torque to mass ratio of the $\mathrm{CMC}$, a parametric analysis of the rotor assemblies is performed. The current design is not fully optimized to reduce the total mass of the coupling and there are several alterations that can be made to reduce the mass further. For example, as shown in Fig. 5b, the flux density of the inner magnet core reduces to an insignificant magnitude beyond a relatively small radial distance from the permanent magnets (towards the shaft). The available core material through which the magnetic field may pass greatly exceeds that required to maintain the optimal magnetic field. The mass of the core can therefore be reduced by cutting slots/holes in the material and reducing the radial back iron thickness beneath the PMs.

Additionally, as shown in the results of the stress analysis performed on the CMC design in Table IV, the peak stress in the shafts and cores is well within their respective material yield strengths and therefore there is room to reduce the shaft diameter for both rotors. The yield strength of the shaft material determines the selected shaft diameter. The current CMC design posseses shafts that are $38 \mathrm{~mm}$ in diameter. In an optimal design, the shaft diameter can be reduced to a minimal value based on (1).

$$
D=\sqrt[3]{\frac{16 T}{\pi \tau_{\text {yield }}}}
$$

Where $T$ is the maximum applied torque, $224 \mathrm{Nm}, \tau_{\text {yield }}$ is the shear yield stress (with a FoS of 1.5) $=78.9 \mathrm{MPa}$, and the shaft diameter, $D=24.36 \mathrm{~mm}$. This is the minimum allowable diameter shaft.

The radius, $R h$ of the four main holes cut into the core along with the thickness of the remaining material columns, L1 is adjusted in the parametric analysis as shown in Fig. 8a. $R h$ was reduced in steps of $5 \mathrm{~mm}$ and $L 1$ was increased in steps of 10 $\mathrm{mm}$. The equivalent stress countour plot for the lowest mass combination of $R h$ and $L 1$ is shown in Fig 9a. This mass was further reduced by adding cut outs within the column structures to further reduce the mass as shown in Fig 9b. The stress results for the final design are shown in Table $\mathrm{V}$ and the selected dimensions are listed in Table VI. For the outer rotor, the outer diameter and the thickness of the supporting steel is reduced until the equivalent stress is close to the minimum allowable value for 316 stainless steel $(118.36 \mathrm{MPa})$. The shaft is removed

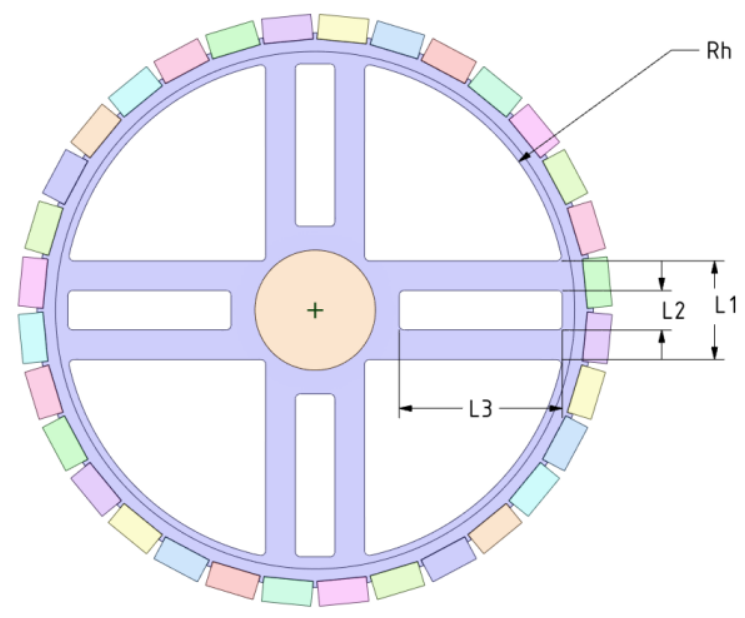

(a)

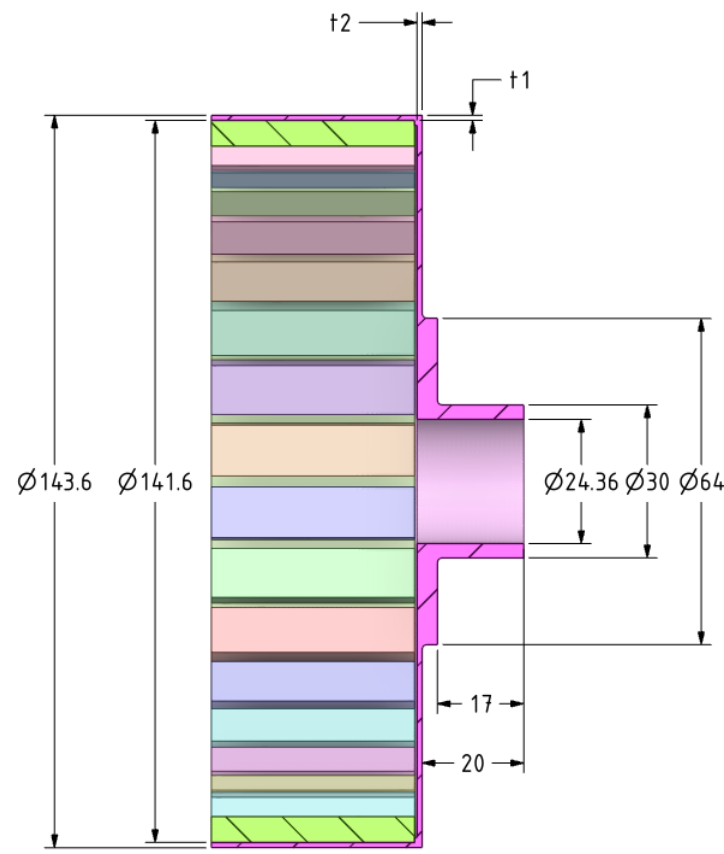

(b)

Fig. 8. (a) Dimension parameters for the inner core (front view), (b) Dimension parameters for the outer shaft (cross section view)

TABLE V. STRESS RESULTS FOR THE OPTIMIZED CMC

\begin{tabular}{|c|c|c|c|c|}
\hline Component & $\begin{array}{c}\text { Peak } \\
\text { Shear } \\
\text { Stress } \\
(\mathbf{M P a})\end{array}$ & $\begin{array}{c}\text { Peak } \\
\text { Equivalent } \\
\text { Stress } \\
(\mathbf{M P a})\end{array}$ & $\begin{array}{c}\text { Mass } \\
\mathbf{( k g )}\end{array}$ & $\begin{array}{c}\text { Volume } \\
\left(\mathbf{m}^{3}\right)\end{array}$ \\
\hline $\begin{array}{c}\text { Inner rotor } \\
\text { core }\end{array}$ & 64.7 & 112 & $\begin{array}{c}1.07 \\
(-1.01)\end{array}$ & $1.38 \mathrm{e}^{-4}$ \\
\hline $\begin{array}{c}\text { Outer rotor } \\
\text { shaft }\end{array}$ & 65.6 & 111 & $\begin{array}{c}0.37 \\
(-5.46)\end{array}$ & $4.6 \mathrm{e}^{-5}$ \\
\hline $\begin{array}{c}\text { Outer rotor } \\
\text { core }\end{array}$ & 2.93 & 5.07 & $\begin{array}{c}0.56 \\
(-0.53)\end{array}$ & $7.2 \mathrm{e}^{-5}$ \\
\hline
\end{tabular}




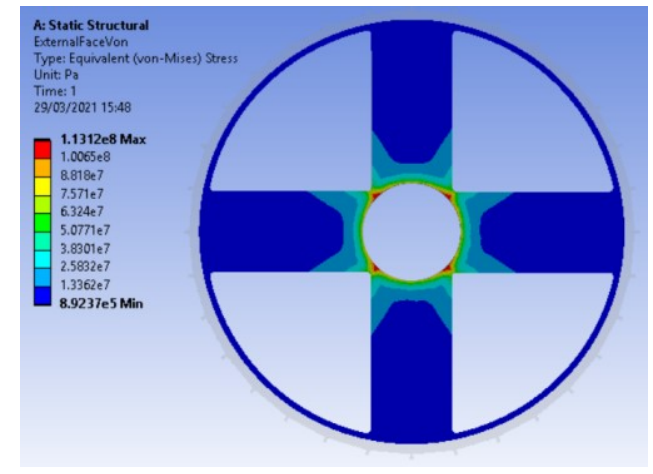

(a)

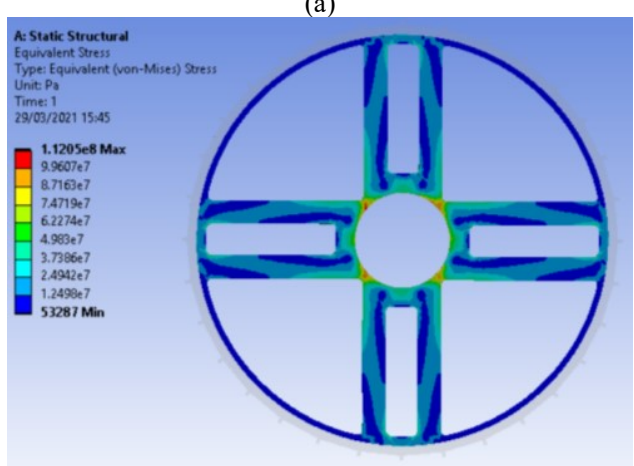

(b)

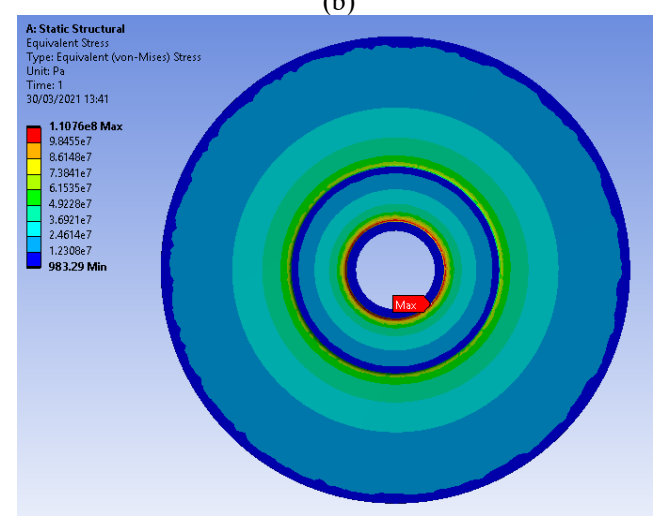

(c)

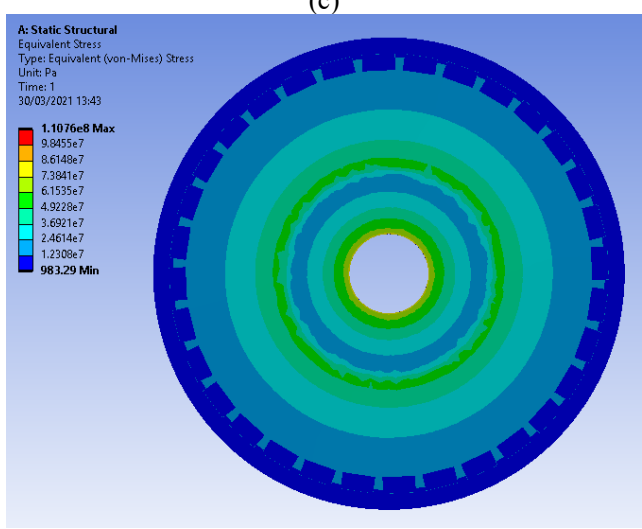

(d)

Fig. 9. (a) Equivalent stress results for the inner rotor (parametric result),

(b) Equivalent stress for the inner rotor, final design, (c) Equivalent stress results for the outer rotor rear view, (d) front view.

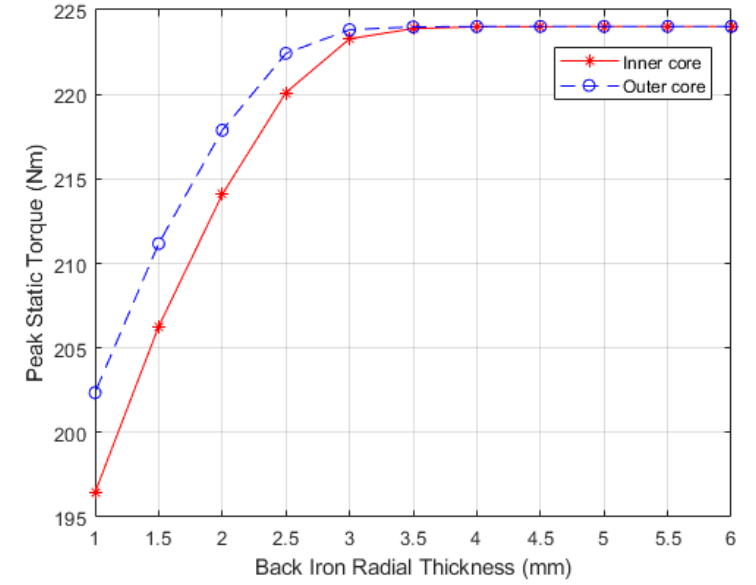

Fig. 10. Peak static torque versus back iron radial thickness for the inner core and outer core

in the analysis and is replaced with a $20 \mathrm{~mm}$ long adaptor with an outer diameter of $30 \mathrm{~mm}$.

The parametric stress analysis is performed taking into account the steady state rotational speed of 1000 RPM and peak transmitted torque of $224 \mathrm{Nm}$. With the volume of material present in the rotor structure of the coupling minimised, the baseline lightweight design of the CMC is established. The resulting geometry obtained from this parametric analysis represents the lightest component that is still capable of withstanding the applied inertial and torsional loads. The total mass of the CMC rotors is reduced from $11.8 \mathrm{~kg}$ to $2.96 \mathrm{~kg}$.

\section{Back Iron Radial Thickness}

The radial thickness of the back iron in the inner and outer rotor cores for the final design is $4 \mathrm{~mm}$, this is the minimum thickness that ensures a peak static torque of $224 \mathrm{Nm}$ that avoids magnetic saturation. As shown in Fig. 10, the peak static torque rapidly falls off when the radial thickness is reduced below $4 \mathrm{~mm}$. This curve was obtained by reducing the radial

TABLE VI. DIMENSIONS OF THE OPTIMIZED CMC

\begin{tabular}{|c|c|}
\hline Dimension & Size (mm) \\
\hline Hole radius $(R h)$ & 51 \\
\hline Column thickness $(L 1)$ & 20 \\
\hline Cut out height $(L 2)$ & 8 \\
\hline Cut out length $(L 3)$ & 33 \\
\hline Outer Shaft thickness $(t 1)$ & 1 \\
\hline Shaft back thickness $(t 2)$ & 1 \\
\hline $\begin{array}{c}\text { Inner core radial } \\
\text { thickness }\end{array}$ & 4 \\
\hline $\begin{array}{c}\text { Outer core radial } \\
\text { thickness }\end{array}$ & 4 \\
\hline
\end{tabular}


TABLE VII. RigID COUPLING PROPERTIES

\begin{tabular}{|c|c|c|c|c|}
\hline Coupling & $\begin{array}{c}\text { Rated } \\
\text { Torque } \\
(\mathbf{N m})\end{array}$ & $\begin{array}{c}\text { Mass } \\
\mathbf{( k g})\end{array}$ & $\begin{array}{c}\text { Torque } \\
\text { to Mass } \\
\text { Ratio } \\
\mathbf{( N m / k g )}\end{array}$ & Material \\
\hline $\begin{array}{c}\text { Ruland MCLC- } \\
\text { 25-25-SS }\end{array}$ & 120 & 0.58 & 206.89 & SS 303 \\
\hline $\begin{array}{c}\text { Ruland MCLC- } \\
\text { 25-25-F }\end{array}$ & 400 & 0.58 & 689.66 & CS 1215 \\
\hline $\begin{array}{c}\text { NBK MRG- } \\
50 \mathrm{~W}\end{array}$ & 25 & 0.189 & 132.28 & Al alloy \\
\hline
\end{tabular}

TABLE VIII. FLEXIBLE COUPLING PROPERTIES

\begin{tabular}{|c|c|c|c|c|}
\hline Coupling & $\begin{array}{c}\text { Rated } \\
\text { Torque } \\
\text { (Nm) }\end{array}$ & $\begin{array}{c}\text { Mass } \\
\text { (kg) }\end{array}$ & $\begin{array}{c}\text { Torque } \\
\text { to Mass } \\
\text { Ratio } \\
\text { (Nm/kg) }\end{array}$ & Material \\
\hline $\begin{array}{c}\text { Mayr ROBA-DS } \\
\text { (single jointed, } \\
\text { clamping hubs) size } \\
\text { 15 }\end{array}$ & 150 & 0.67 & 223.88 & SS disk \\
\hline $\begin{array}{c}\text { Mayr ROBA-DS } \\
\text { size 16 (single } \\
\text { jointed with key } \\
\text { hubs) }\end{array}$ & 300 & 1 & 300 & SS disk \\
\hline $\begin{array}{c}\text { Mayr ROBA-DS } \\
\text { size 25 (double } \\
\text { clamping hub) }\end{array}$ & 420 & 3.54 & 118.64 & SS disk \\
\hline $\begin{array}{c}\text { SKF Single-flex } \\
\text { (W4) - Size 20, } \\
\text { bolt single (bore not } \\
\text { included) }\end{array}$ & 245 & 2.5 & 98 & SS disk \\
\hline $\begin{array}{c}\text { Ruland MDCSK51- } \\
\text { 25-12-A }\end{array}$ & 39.6 & 0.2 & 198 & Al hubs \\
SS disk \\
\hline
\end{tabular}

back iron thickness in $0.5 \mathrm{~mm}$ steps with the $2 \mathrm{D}$ magnetostatic solver used in Section III.

The stress in the back iron with a $4 \mathrm{~mm}$ radial thickness is within acceptable limits and it is possible to reduce the thickness further from a mechanical perspective, although not without significantly reducing the peak static torque capacity of the $\mathrm{CMC}$.

\section{Torque to Mass Ratio Comparison}

The torque to mass ratio of the $\mathrm{CMC}$ rotors is increased from $18.98 \mathrm{Nm} / \mathrm{kg}$ to $75.68 \mathrm{Nm} / \mathrm{kg}$. An increase of $398.7 \%$. One of the most simple and lightweight types of mechanical coupling is the rigid, single or two-piece coupling. This type of coupling typically includes a clamping mechanism on both shaft bores and the torque is transferred through a solid steel coupling body. It is well known that magnetic couplings offer distinct advantages of rigid mechanical couplings such as inherent overload protection, but magnetic couplings are usually much heavier and thus have a lower torque to mass ratio. A brief study of the average torque to mass ratio of some commercially available rigid couplings is conducted here, the results of which are shown in Table VII and Table VIII. These specifications are available on the manufacturer web pages [13], [14], [15] and [16]. The bore diameter is fixed at $25 \mathrm{~mm}$ for the rigid couplings, maximum diameter for the flexible Mayr couplings and no bore is included in the SKF coupling mass.

Note that the rated torque is lower than the peak torque for such couplings, but the couplings should normally be selected based on their rated torque value, with peak torque considered only for expected overload conditions / transients. The materials used in the construction of mechanical couplings largely determines their rated torque. Stainless steel (SS), aluminum alloy (Al) and carbon steel (CS) are utilized in the different couplings. The torque to mass ratio of the optimized CMC could be increased further by selecting higher strength to weight ratio materials to support the inner magnets, with a layer of the existing electrical steel remaining in place to act as the required back iron for the PMs. Further reductions in mass would however be relatively minor. The comparison in torque to weight ratio assumes that the inner and outer rotors of the $\mathrm{CMC}$ are pressed directly to the machine shafts and no housing is included.

As result, the optimized $\mathrm{CMC}$ has a torque to weight ratio comparable with that featured by the flexible disc coupling, SKF Single flex (W4), although improvements are still required to reach the typical values of commercially available mechanical couplings.

\section{E. Dynamic Structural Analysis}

As the geometry of the inner rotor core has changed significantly following its redesign for mass reduction, a modal analysis is performed for both the original and optimized inner rotors to observe the impact of reduced lateral and torsional stiffness on the first four modal frequencies. The shafts for both versions of the inner rotor are included to provide support for the analysis.

The critical speeds (below 20,000 RPM) are also obtained and compared with the target operating speed of 1000 RPM to ensure the device does not resonate at one or more modes of vibration during normal operation. The modal results for the inner rotor and outer rotor of the original CMC and optimized $\mathrm{CMC}$ are shown in Table IX and Table $\mathrm{X}$ respectively. In all following simulations the rotors are fixed with cylindrical joints at the ends of their shafts rather than their bearing locations to

TABLE IX. MOdAL RESUlts FOR THE ORIGINAL CMC DESIGN

\begin{tabular}{|c|c|c|c|c|}
\hline $\begin{array}{c}\text { Mode } \\
\text { Number }\end{array}$ & Rotor & $\begin{array}{c}\text { Frequency } \\
(\mathbf{H z})\end{array}$ & $\begin{array}{c}\text { Mode } \\
\text { Shape }\end{array}$ & $\begin{array}{c}\text { Critical } \\
\text { Speed } \\
\text { (RPM) }\end{array}$ \\
\hline 1 & Inner & 202.62 & Torsional & 12157 \\
\hline 2 & Inner & 480.03 & Lateral & - \\
\hline 3 & Inner & 480.05 & Lateral & - \\
\hline 4 & Inner & 3032.7 & Lateral & - \\
\hline 1 & Outer & 78.85 & Torsional & 4731.1 \\
\hline 2 & Outer & 249.22 & Lateral & 10526 \\
\hline 3 & Outer & 249.3 & Lateral & - \\
\hline 4 & Outer & 775.43 & Lateral & - \\
\hline
\end{tabular}


TABLE X. MOdAl RESUlTS FOR THE OPTIMIZED CMC DESIGN

\begin{tabular}{|c|c|c|c|c|}
\hline $\begin{array}{c}\text { Mode } \\
\text { Number }\end{array}$ & Rotor & $\begin{array}{c}\text { Frequency } \\
(\mathbf{H z})\end{array}$ & $\begin{array}{c}\text { Mode } \\
\text { Shape }\end{array}$ & $\begin{array}{c}\text { Critical } \\
\text { Speed } \\
(\mathbf{R P M})\end{array}$ \\
\hline 1 & Inner & 126.52 & Torsional & 7591.4 \\
\hline 2 & Inner & 283.63 & Lateral & 15010 \\
\hline 3 & Inner & 283.65 & Lateral & 19745 \\
\hline 4 & Inner & 1537 & Lateral & - \\
\hline 1 & Outer & 96.7 & Torsional & 5802.1 \\
\hline 2 & Outer & 128.4 & Lateral & 5261 \\
\hline 3 & Outer & 128.5 & Lateral & - \\
\hline 4 & Outer & 298.6 & Axial & 17913 \\
\hline
\end{tabular}

allow for direct comparison between the two CMC geometries as the optimized design does not include bearings.

The lateral and torsional modal frequencies of the inner rotor are significantly reduced, and the lateral frequencies of the outer rotor are also reduced. The critical speeds are still well in excess of the 1000 RPM operating speed for the optimized design. However, if the operating speed were to be increased, both the parametric stress analysis and modal analysis would need to be performed again to ensure that the design can withstand the increase in rotational forces and does not operate near any critical speeds in order to prevent resonance. More material would need to be added to the structure as the speed is increased to withstand the increased stress, which in turn will also reduce the frequencies of the modes shown in Table X.

\section{CONCLUSIONS}

A CMC is optimised to achieve a high torque to mass ratio by firstly performing a $2 \mathrm{D}$ magnetostatic analysis to validate that the target peak static torque of $224 \mathrm{Nm}$ is achieved for the minimum required geometric dimensions. The stress within the rotor structures is then analysed and a parametric stress analysis is performed to maximise the torque to mass ratio of the $\mathrm{CMC}$ further by removing unnecessary material whilst maintaining structural integrity under the rated load conditions. The torque to mass ratio of the initial CMC design is increased by a factor of 3.98 , to $75.68 \mathrm{Nm} / \mathrm{kg}$. The final optimised design compares more favourably with existing commercially available mechanical couplings, particularly flexible disc type couplings with clamp fittings. The critical speeds that were obtained from a modal analysis of the optimised design are sufficiently larger than the rated operating speed and so it remains practical to operate the device at both its rated speed and well beyond. The CMC is still relatively stiff, despite the geometric modifications that have been made.

\section{ACKNOWLEDGMENT}

This work was supported by the Clean Sky 2 Joint Undertaking through the European Union's Horizon 2020
Research and Innovation Programme under Grant 807081 and Grant 821023.

\section{REFERENCES}

[1] M. Galea, P. Giangrande, V. Madonna and G. Buticchi, "ReliabilityOriented Design of Electrical Machines: The Design Process for Machines' Insulation Systems MUST Evolve," in IEEE Industrial Electronics Magazine, vol. 14, no. 1, pp. 20-28, March 2020.

[2] M. Lukic et al., "State of the Art of Electric Taxiing Systems," 2018 IEEE International Conference on Electrical Systems for Aircraft, Railway, Ship Propulsion and Road Vehicles \& International Transportation Electrification Conference (ESARS-ITEC), Nottingham, UK, 2018, pp. 1-6.

[3] Y. Akcay, P. Giangrande and M. Galea, "Design, Analysis and Dynamic Performance of Radial Magnetic Coupling," 2020 23rd International Conference on Electrical Machines and Systems (ICEMS), Hamamatsu, Japan, 2020, pp. 222-227.

[4] E. P. Furlani, R. Wang and H. Kusnadi, "A three-dimensional model for computing the torque of radial couplings," in IEEE Transactions on Magnetics, vol. 31, no. 5, pp. 2522-2526, Sept. 1995.

[5] W. Wu, H. C. Lovatt and J. B. Dunlop, "Analysis and design optimisation of magnetic couplings using 3D finite element modelling," in IEEE Transactions on Magnetics, vol. 33, no. 5, pp. 4083-4094, Sept. 1997.

[6] M. H. Nagrial, "Analysis, design and performance of magnetic couplings," Proceedings of 1995 International Conference on Power Electronics and Drive Systems. PEDS 95, Singapore, 1995, pp. 634638 vol.2.

[7] M. Lukic, P. Giangrande, A. Hebala, S. Nuzzo and M. Galea, "Review, Challenges, and Future Developments of Electric Taxiing Systems," in IEEE Transactions on Transportation Electrification, vol. 5, no. 4, pp. 1441-1457, Dec. 2019.

[8] Y. Akcay, P. Giangrande and M. Galea, "A Novel Magnetic Coupling Configuration for Enhancing the Torque Density," 2020 23rd International Conference on Electrical Machines and Systems (ICEMS), Hamamatsu, Japan, 2020, pp. 228-233.

[9] P. Giangrande, V. Madonna, G. Sala, A. Kladas, C. Gerada and M. Galea, "Design and Testing of PMSM for Aerospace EMA Applications," IECON 2018 - 44th Annual Conference of the IEEE Industrial Electronics Society, Washington, DC, USA, 2018, pp. 20382043.

[10] J. Park, S. Paul, J. Chang, T. Hwang, J. Yoon, "Design and comparative survey of high torque coaxial permanent magnet coupling for tidal current generator," Int. J. of Elec. Power \& Energy Systems, vol. 120, September 2020.

[11] T. Lubin, S. Mezani and A. Rezzoug, "Simple Analytical Expressions for the Force and Torque of Axial Magnetic Couplings," in IEEE Transactions on Energy Conversion, vol. 27, no. 2, pp. 536-546, June 2012.

[12] Factors of Safety, The Engineering Toolbox, April 2021. [Online]. Available: https://www.engineeringtoolbox.com/factors-safety-fosd_1624.html

[13] Rigid Couplings, Ruland Manufacturing, April. 2021. [Online]. Available: https://www.ruland.com/rigid-couplings.html

[14] MRG-W Rigid Couplings - Split Type, Nabeya Bi-tech Kaisha, April 2021. [Online]. Available: https://www.nbk1560.com/en/products/coupling/couplicon/rigid_type/ MRG-W/?SelectedLanguage $=$ en

[15] Shaft Couplings, Mayr, April 2021. [Online]. Available: https://www.mayr.com/en/products/shaft-couplings/roba-ds-steel

[16] Couplings, SKF, April 2021. [Online]. Available: https://www.skf.com/uk/products/power-transmission/coupling 